\title{
Depression Across the Species
}

\author{
Álvaro Machado Dias*, Ana Karina Santos, Margareth Yuri Takeuchi and Cristina Harumi Adania
}

\author{
University of São Paulo, Psychology Institute, Dept. of Neuroscience and Behavior (IP-NEC-USP). Av. Prof. Mello \\ Moraes, 1721 Caixa Postal 66261 Cidade Universitária, São Paulo, Brazil
}

\begin{abstract}
Backgrounds: this article has two close related goals. First it reviews the current literature on animal models of depression, using data mining techniques. Second it discusses whether it is feasible or not to extend the concept of depression to non-humans. Results: the use of animal models of depression increased dramatically over the last years, in association with the development of new drugs and genetic studies. On the other hand, the possibility to assume a strong correlation between human depression and low mood in other mammals remains unfeasible. Human depression represents a 'reaching-point', both at the organic and the phenomenological levels; nosographically, it can be asserted only within the horizon of possibilities represented by alternative disorders with which it shares common features.
\end{abstract}

Keywords: Depression, etiology, evolution, humans, animals.

\section{INTRODUCTION}

Psychiatric depression (major depression) is a serious disorder intrinsically related to low mood, and secondarily associated to other signs [1]. Although the history of psychopathology involves a variety of epistemological perspectives on psychiatric disease classification (nosography), most scientists and clinicians nowadays adopt one of the following conceptions: either the disorder is defined primarily on a descriptive phenomenological basis (as in the DSM) or it is associated intrinsically to etiological constraints, as in the CID manual (for a review of this point: [2]).

Within the descriptive phenomenological mode, current attempts to diagnose and treat 'depressive animals' have proliferated. While this tendency may be assumed to be a pragmatic, valid approach to animal suffering in captivity, it does raise some issues in relation to the extensions and limits of the conception of depression, in a way that symptomatological isomorphism cannot satisfy. Descriptive phenomenological approaches themselves do not guarantee that descriptive similarities support the extending concept of depression to other species, because nosographic validity rest, precisely, on similarity among humans, based on the assumption that deep level variables should accompany descriptive ones. Thus, no matter what framework is adopted, the analytical possibilities of inter-species nosography imply the definition of the deep level correlations between the different species.

Shifting to the history of psychopathology, one finds canonical perspectives in regard to animal models of depression (in distinction to models of animal depression), as

*Address correspondence to this author at the University of São Paulo, Psychology Institute, Dept. of Neuroscience and Behavior (IP-NEC-USP). Av. Prof. Mello Moraes, 1721 Caixa Postal 66261 Cidade Universitária, São Paulo, Brazil; Tel: 00-55-11-3082-5919; E-mail: alvaromd@usp.br first systematized by McKinney and Bunney [3]. According to these authors, the main features of animal models of depression include their biological and behavioral similarities to humans (e.g. anhedonia, high cortisol level), response to treatment (behavioral reversibility), and the possibility of experimental replication.

Although some of the general characteristics of this perspective remain valid, it is important to recognize that in those days, experimental paradigms using animal models were considerably narrower than the current set. For example, we cannot expect that animal models involving a great number of genetic mutations show complete behavioral reversals by means of any treatment. In other words, current animal models are categorically divided in terms of the function that they need to serve: the model used to test the importance of a gene is not necessarily the same as the one employed to test the efficacy of a treatment, and so on.

This perspective affects the epistemological foundations of etiological research and possible inter-species correlations, as the specificity of deep level variables (genetic and epigenic) and descriptive level variables (brain and behavioral) of psychiatric disorders increase, and should be discussed in detail when comparing humans with other species.

The purpose of this article is to review and critically discuss the main convergences and divergences at both genetic and descriptive phenomenological levels, in regard to depression. In order to achieve this objective, we begin with a review of the recent literature on the main topics of interest. We included both a conceptual map (Fig. 1) and a thematic map (Fig. 2) of all studies on animal models of depression, indexed in PubMed and/or ISI in 2008/2009. We then proceed to review specific findings in brain/behavior and genetics in order to produce a sensible picture about the epistemological constraints determined by the human boundaries of the concept of psychiatric depression. In the 


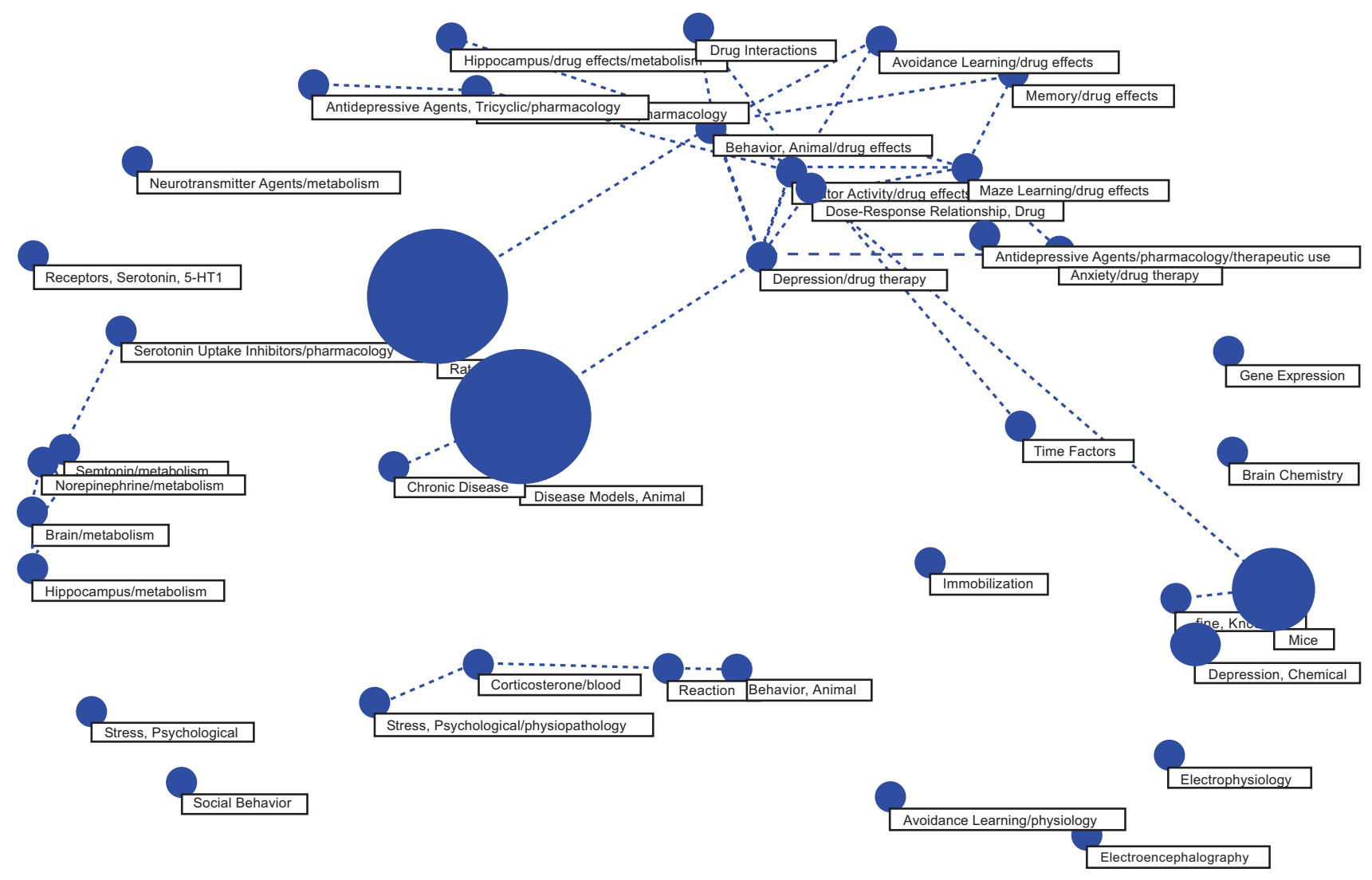

Fig. (1). Main concepts in the current field of animal models of depression.

last section, we also provide an algorithm (Fig. 3) to make a synthesis of our main findings.

\section{TOPOLOGICAL REVIEW WITH DATA MINING: MAIN CONCEPTS AND THEMATIC CLUSTERING OF THE STUDIES ON ANIMAL MODELS OF DEPRESSION (2008-2009)}

Covering the period January 2008 to February 2009, we identified 73 indexed publications in PubMed or ISI adopting animal models of depression, which suggests that a considerable number of scientists accept this to be a valid model for this human disorder. Below we present the main concepts in the field, as much as their core associations.

As much as one can notice and data mining reveals, these concepts belong to studies that can be associated into thematic clusters. In the topological map below, these studies are divided into seven topics.

The thematic representation of the field identifies several closely related clusters, which suggests that many authors and labs cover more than one of the topics. This is especially true in relation to the response to stressful tasks in accordance with different brain and/or genetic profiles. In our estimation, different tasks may represent dependent variables in experimental paradigms related to genetic variations (e.g. polymorphisms related to depression) and associated brain abnormalities (e.g. cortical dysfunction associated to that polymorphism).
The map also suggests that most of the studies are related to the development and evaluation of antidepressants. Twenty-five studies deal directly with antidepressants; while at the same time, nearly all the remaining studies potentially have a bearing on that subject (further evidence can be extracted from the first map).

One final feature worth highlighting is that animal-based research on the hippocampus in depression has become prominent. In our view, these studies may be associated with the tendency to consider the designs and effects of treatment in terms of their influence on neural plasticity, which currently is a hot topic in the field, after decades when the dominant paradigm denied neurogenesis in the adult brain.

\section{DESCRIPTIVE CORRELATIONS: FROM LOW MOOD TO MAJOR DEPRESSION}

The strongest evidence of the possibility to extend the medical concept of depression to non-humans is represented by the animal models of depression used under drug testing [4]. Mouse models revealed that antidepressants can reduce immobility and even produce a total behavioral shift from anhedonia to persistent struggle in the tail suspension test [5-7]. Early exposure to maternal separation is associated with increased risk of stress-induced hyperalgesia, simulating features of irritable bowel syndrome in mice [8]. This syndrome has been associated with chronic stress and depression in humans $[9,10]$. Monkey models of depression show diminished ' $1 \mathrm{a}$ ' serotonin receptors in association with clinical signs of the disorder [11]. Other experiments on 


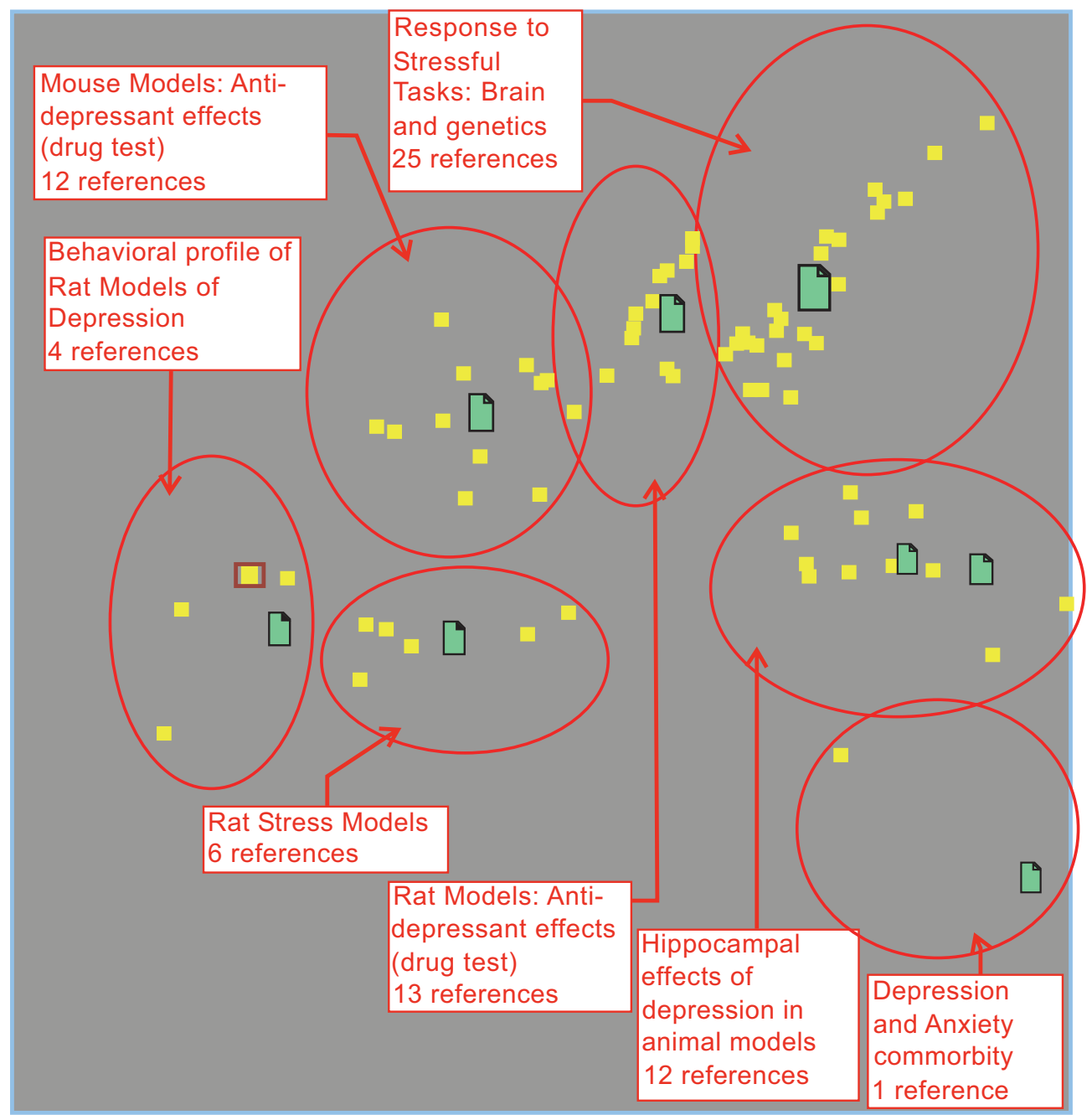

Fig. (2). Thematic Map of the 2008/2009 studies on animal model of depression.

monkeys suggested that early stress caused by familial separation predisposed the animals to manifest depressivelike behaviors when reunited to the group [12], and that this effect persisted for years [13] (a follow-up study [14] confirmed these assumptions). Together these perspectives resemble prominent theories about human depression etiology, which commonly associate genetic risk factors and exposure to critical conditions.

That said, it is important to acknowledge that there may be reasons not to consider these findings as indicative of a straightforward correlation -at least not before submitting them to a careful scrutiny, and taking into account some other findings. Considering the early stress paradigm (highly pertinent to the humans) a recent study with mutant mice did confirm that the mutant cohort exhibited decreased proximity-seeking behavior, but also noticed that this had little to do with the effects of the experimental paradigm, and mostly with the mutations per se. This perspective not only modifies previous deterministic perspectives on experimental induction of depression, but also it departs from the intrinsic nature-nurture profile of human depression [15].
On the other hand, an experiment testing the effects of green leaf odor on the depressive behavior of mice without genetic modification and submitted to experimental models of stress, suggested that mouse depression might not be as strong and persistent as psychiatric depression [16].

Finally, and in a more striking fashion, there is a mismatch between depression and the stress-despair paradigm, which is generally applied in experimental settings of animal models of depression. Let us consider the following example: induced stress experiments on mammals reveal that chronic stress leads to central noradrenergic (NA) depletion and increased adrenergic (Ad) and noradrenergic serine levels, much in the same way that it occurs in cases of major depression. Nonetheless, while the ratio NA/Ad is increased in the latter, it is decreased in former experimental conditions [17]. In other words, the neurochemical profile of major depression cannot be simulated under stress-despair experimental conditions, which represent the core animal models of human depression.

Thus, there is no animal model of major depression in the strict sense in many of the aforementioned circumstances, but rather an animal model of stress/despair within which similarities indeed proliferate, along with differences. 


\section{GENETIC CORRELATIONS}

Genetic correlations between humans and animals of other species in relation to depression proneness emerged as a consistent hypothesis before the rise of genomics, along with the perspective that depression is not culturally contingent, and thus could not be assumed exclusively as an effect of modern life styles. The main evidence for this assumption is represented by reports of depression among hunters and gathers like the !Kung [18] and the Eskimos of the Bering Strait [19]. Additional support for this perspective comes from descriptions of depressive states among wild animals in natural habitats, mainly associated to maternal abandonment $[20,21]$.

With regard to these findings, the main genetic axis associated with depression is related to alleles of the serotonin gene that participate in the serotonin synthesis and transport cascade, where the presence of one or more copies of the short allele (5-HTTLPR) in the promoter region of the gene (5-HTT) represents the strongest risk factor for the disorder [22-28]. The 5-HTT alleles are related to the formation of the transmembrane that activates the serotonin reuptake in the pre-synaptic cell, and the 5-HTTLPR polymorphism is associated with decreased response to antidepressants [29].

The presence of short alleles is related to abnormal serotonergic signaling both in humans [30] and in Rhesus monkeys submitted to chronic stress [22]. This is contrary to the hypothesis of genetic differences between man and monkey by means of recent mutations, and potentially indicative of a deep correlation. According to Olsen et. al, "A44bp insertion/deletion polymorphism in a GC-rich repetitive sequence in the 50 regulatory region of the 5-HTT gene (5-HTTLPR) is thought to have been introduced into the genome around 40 million years ago, and has homologous forms in the chimpanzee, orangutan, gorilla and macaque" [25] (p. 868).
Nonetheless, it is important to acknowledge that the etiology of depression is related to vulnerability (identical twins reveal a $69 \%$ correlation for the disorder [31]) and not to determinism [22, 24]. This vulnerability effect can explain findings such as diminished but not inexistent incidence among isolated ethnic groups, in relation to western urban populations [32], and the fact that epigenic abnormalities (e.g. methylations) represent a significant risk factor for depression in humans [33-37].

With that in mind, we can assume that depression is indeed related to recurrent polymorphisms, like the 5HTTLPR [38] and others. Nevertheless, we should also consider that these same polymorphisms have been associated not only to depression, but also to obsessivecompulsive disorder (for a meta-analysis with over three thousand cases: [39], migraines with aura [40], chronic anxiety [26, 41, 42], and alcohol abuse [25, 43, 44]. Whether they are associated to other disorders remains open to controversy [25].

It seems reasonable to assume that each particular genetic risk factor associated with depression does not determine the disorder, but contributes to the structural consolidation of abnormal affective pathways, which, in association to other features can lead to depression, or to chronic anxiety, migraines with aura and other complex disorders. In support of this idea, a recent study revealed that the short alleles of the 5-HTTLPR are associated with selective attention to unconditioned threatening stimuli (spiders) [45], which is a trait co-present in many disorders, while (in the same sense) another related short allele (S) homozygous to increased stress reactivity [46].

Hence, human depression is unique because it represents an inversion of the NA/ad relation and exhibits some exclusive features in relation to animal models of depression within the stress/despair paradigm or mutant constructs. Moreover, human depression emerges in a context where many collateral disorders represent alternative pathways and

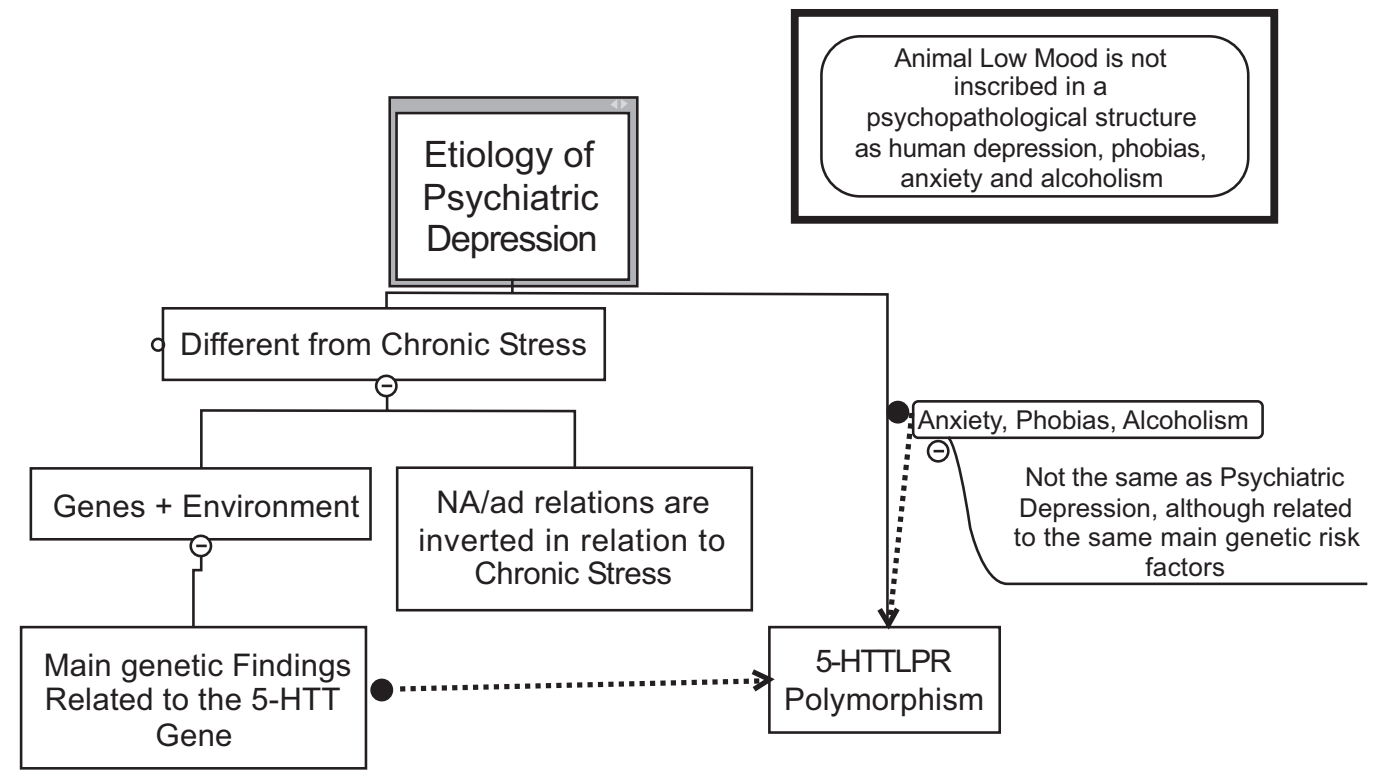

Fig. (3). Psychiatric depression as a disorder inscribed in psychopathology's structure. 
constraints to the determination of the clinical phenomenon, which cannot be predicted solely by genetic risk factors, as they may be shared by other disorders.

Psychiatric disorders are always diagnosed by excluding other possible causes for the symptoms. This is one of the keys to the most profound difference between human and animal psychopathology, and thus to the deepest difference between human and animal depression. A patient suffering from major depression that manifests a manic episode will have his diagnosis switched to a bipolar disorder; a patient suffering from anxiety that begins to manifest itself as a long lasting low mood will receive a new diagnose: major depression, and so on. In the final analysis, the fact that human psychopathology has essential collateral relations in both etiological and nosographic levels, remains as it's most exclusive feature.

Above, we propose an algorithm to display this perspective (Fig. 3).

\section{CONCLUSIONS}

As an answer to the question that inspired this paper, we can assert that it is not sensible to assume a strong correlation between human depression and low mood in any other species. At the same time, we can assume that reducing the concept of major depression to the output of the stressdespair paradigm represents a very problematical maneuver.

Depression represents a 'reaching-point', both at the organic and the phenomenological level, within which nosography acquires a structural form. Thus, depression can be asserted only within the horizon of possibilities represented by alternative disorders with which it shares common features at genetic, organic and symptomatological levels. It is precisely this peculiarity that establishes the uniqueness of human depression, despite the unequivocal strategic application of animal constructs.

\section{REFERENCES}

[1] Lewis AJ. Melancholia: a clinical survey of depressive states. J Ment Sci 1934; 80(329): 277-378.

[2] Parshall AM, Priest AG. Nosology, taxonomy and the classification conundrum of the functional psychoses. Br J Psychiatry 1993; 162: 227-36.

[3] McKinney WT Jr, Bunney WE Jr. Animal model of depression: i. review of evidence: implications for research. Arch Gen Psychiatry 1969; 21(2); 240-8.

[4] Deussing JM. Animal models of depression. Drug Discov Today Dis Models 2006; 3(4): 375-83.

[5] Cryan JF, Mombereau C, Vassout A. The tail suspension test as a model for assessing antidepressant activity: review of pharmacological and genetic studies in mice. Neurosci Biobehav Rev 2005; 29(4-5): 571-625.

[6] Cryan JF, Markou A, Lucki I. Assessing antidepressant activity in rodents: recent developments and future needs. Trends Pharmacol Sci 2002; 23(5): 238-45.

[7] Liu X, Peprah D, Gershenfeld HK. Tail-suspension induced hyperthermia: a new measure of stress reactivity. J Psychiatr 2003; 37(3): 249-59.

[8] Coutinho SV, Plotsky PM, Sablad M, et al. Neonatal maternal separation alters stress-induced responses to viscerosomatic nociceptive stimuli in rats. Am J Physiol Gastrointest Liver Physiol 2002; 282(2): G307-16.

[9] Maunder RG, Levenstein S. The role of stress in the development and clinical course of inflammatory bowel disease: epidemiological evidence. Curr Mol Med 2008; 8: 247-52.
[10] Ghia JE, Blennerhassett P, Collins SM. Vagus nerve integrity and experimental colitis. Am J Physiol Gastrointest Liver Physiol 2007; 293(3): G560-7.

[11] Shively CA, Friedman DP, Gage HD. Behavioral depression and positron emission tomography-determined serotonin la receptor binding potential in cynomolgus monkeys. Arch Gen Psychiatry 2006; 63(4): 396-403.

[12] Young LD, Suomi SS, Harlow HF, McKinney WT Jr. Early stress and later response to separation in rhesus monkeys. Am J Psychiatry 1973; 130(4): 400-5.

[13] Hinde RA, Spencer-Booth Y. Effects of brief separation from mother on rhesus monkeys. Science 1971; 173(992): 111-8.

[14] Capitanio JP, Rasmussen KL, Snyder DS, Laudenslager M, Reite M. Long-term follow-up of previously separated pigtail macaques: group and individual differences in response to novel situations. J Child Psychol Psychiatry 1986; 27(4): 531-8.

[15] Braw Y, Malkesman O, Merenlender A, et al. Withdrawal emotional-regulation in infant rats from genetic animal models of depression. Behav Brain Res 2008; 193(1): 94-100.

[16] Nakatomi Y, Yokoyama C, Kinoshita S, et al. Serotonergic mediation of the antidepressant-like effect of the green leaves odor in mice. Neurosci Lett 2008; 436(2): 167-70.

[17] Lechin F, Van der Dijs B, Benaim M. Stress versus depression. Prog Neuropsychopharmacol Biol Psychiatry 1996; 20(6): 899950.

[18] Howell N. The demography of the Dobe !Kung. New York: Academic Press 1979.

[19] Aoun SL, Gregory RJ. Mental disorders of eskimos seen at a community mental health center in Western Alaska. Psychiatr Serv 1998; 49(11): 1485-7.

[20] Harlow HF. Love in infant monkeys. Sci Am 1959; 200(6): 68-73.

[21] Goodall J. The behavior of chimpanzees in their natural habitat. Am J Psychiatry 1973; 130: 1-12.

[22] Caspi A, Sugden K, Moffitt TE, et al. Influence of life stress on depression: moderation by a polymorphism in the 5-HTT gene. Science 2003; 301(5631): 386-9.

[23] Hoefgen B, Schulze TG, Ohlraun S, et al. The power of sample size and homogenous sampling: association between the 5HTTLPR serotonin transporter polymorphism and major depressive disorder. Biol Psychiatry 2005; 57(3): 247-51.

[24] Levinson DF, The genetics of depression: a review. Biol Psychiatry 2006; 60(2): 84-92.

[25] Olsson CA, Byrnes GB, Lotfi-Miri M, et al. Association between 5-HTTLPR genotypes and persisting patterns of anxiety and alcohol use: results from a 10-year longitudinal study of adolescent mental health. Mol Psychiatry 2005; 10(9): 868-76.

[26] Serretti A, Mandelli L, Lorenzi C, Smeraldi E. Social adjustment could be associated with the serotonin transporter gene in remitted patients with mood disorders and healthy subjects. Psychiatry Res 2005; 134(2): 191-4.

[27] Kumakiri C, Kodama K, Shimizu E, et al. Study of the association between the serotonin transporter gene regulatory region polymorphism and personality traits in a Japanese population. Neurosci Lett 1999; 263(2-3): 205-7.

[28] Lazary J, Lazary A, Gonda X. New Evidence for the Association of the Serotonin Transporter Gene (SLC6A4) Haplotypes, Life Threatening Events, and Depressive Phenotype. Biol Psychiatry 2008; 64(6): 498-504.

[29] Zanardi R, Benedetti F, Di Bella D, Catalano M, Smeraldi E. Efficacy of paroxetine in depression is influenced by a functional polymorphism within the promoter of the serotonin transporter gene. J Clin Psychopharmacol 2000; 20(1): 105-7.

[30] Carola V, Frazzetto G, Pascucci T, et al. Identifying molecular substrates in a mouse model of the serotonin transporter $x$ environment risk factor for anxiety and depression. Biol Psychiatry 2008; 63(9): 840-6.

[31] Kendler KS, Pedersen N, Johnson L, Neale MC, Mathé AA. A pilot Swedish twin study of affective illness, including hospital- and population-ascertained subsamples. Arch Gen Psychiatry 1993; 50(9): 699-700.

[32] Ahmed K, Bhugra D. Diagnosis and management of depression across cultures. Psychiatry 2006; 5(11): 417-9.

[33] Almeida OP, Flicker L, Lautenschlager NT, Leedman P, Vasikaran $\mathrm{S}$, van Bockxmeer FM. Contribution of the MTHFR gene to the causal pathway for depression, anxiety and cognitive impairment in later life. Neurobiol Aging 2005; 26(2): 251-7. 
[34] Czesak M, Lu J, Stockmeier C, Austin M, Meltzer H, Albert P. DNA methylation at 5-HT1A receptor promoter C(-1019)G polymorphism $\mathrm{CpG}$ sites in schizophrenia and depression. J Affect Disord 2008; 107(Suppl 1): S74.

[35] De Vanna M, Rigamonti R. Oral S-adenosyl-L-methionine in depression. Curr Therapeutic Res 1992; 52(3): 478-85.

[36] Reynolds EH, Carney MWP, Toone BK. Methylation and mood. Lancet 1984; 324(8396): 196-8.

[37] Tsankova N, Renthal W, Kumar A, Nestler EJ. Epigenetic regulation in psychiatric disorders. Nat Rev Neurosci 2007; 8(5): 355-67.

[38] Chotai J, Serretti A, Lattuada E, et al. Gene-environment interaction in psychiatric disorders as indicated by season of birth variations in tryptophan hydroxylase (TPH), serotonin transporter (5-HTTLPR) and dopamine receptor (DRD4) gene polymorphisms. Psychiatry Res 2003; 119(1-2): 99-111.

[39] Lin, P-Y. Meta-analysis of the association of serotonin transporter gene polymorphism with obsessive-compulsive disorder. Prog Neuropsychopharmacol Biol Psychiatry 2007; 31(3): 683-9.
[40] Borroni B, Brambilla C, Liberini P, et al. Functional serotonin 5HTTLPR polymorphism is a risk factor for migraine with aura. $\mathrm{J}$ Headache Pain 2005; 6(4): 182-4.

[41] Murphy DL, Li Q, Engel S, et al. Genetic perspectives on the serotonin transporter. Brain Res Bull 2001; 56(5): 487-94.

[42] Katsuragi S, Kunugi H, Sano A, et al. Association between serotonin transporter gene polymorphism and anxiety- related traits. Biol Psychiatry 1999; 45(3): 368-70.

[43] Hammoumi S, Payen A, Favre JD, et al. Does the Short Variant of the Serotonin Transporter Linked Polymorphic Region Constitute a Marker of Alcohol Dependence? Alcohol 1999; 17(2): 107-12.

[44] Pinto E, Reggers J, Gorwood P, et al. The short allele of the serotonin transporter promoter polymorphism influences relapse in alcohol dependence. Alcohol Alcohol 2008; 43(4): 398-400.

[45] Osinsky R, Reuter M, Küpper Y, et al. Variation in the serotonin transporter gene modulates selective attention to threat. Emotion 2008; 8(4): 584-8.

[46] Gotlib IH, Joormann J, Minor KL, Hallmayer J. HPA axis reactivity: a mechanism underlying the associations among 5HTTLPR, stress, and depression. Biol Psychiatry 2008; 63(9): 84751.

(C) Dias et al.; Licensee Bentham Open.

This is an open access article licensed under the terms of the Creative Commons Attribution Non-Commercial License (http://creativecommons.org/licenses/by$\mathrm{nc} / 3.0 /$ ) which permits unrestricted, non-commercial use, distribution and reproduction in any medium, provided the work is properly cited. 